\title{
The availability of new potato cross-breeds for industrial processing
}

\author{
Soltan Soslanbekovich Basiev*, Petr Zaharovich Kozaev, Asia Taimurazovna Doeva, and \\ Diana Petrovna Kozaeva
}

Federal State Budgetary Educational Institution Of Higher Education "Gorsky State Agrarian University", 362040 RNO-Alanya, Vladikavkaz, Russia

\begin{abstract}
Under the conditions of the Republic of North Ossetia-Alania, an assessment of the availability of new cross-breeds of their own breeding to industrial processing of French fries according to morphological, biochemical and consumer quality indices has been carried out. It has been specified that the requirements for tubers on morphological grounds for the production of French fries are satisfied by cross-breeds 10.11/53 and $10.11 / 804$, characterized by an elongated form of tuber, flat and smooth surface, shallow depth of the eyes. According to the quality of the finished product we should select the cross-breed 10.11/1787 due to the faintly darkening pulp of the frozen semi-finished product, the attractive appearance of the finished French fries, their good taste and smell. Crossbreeds 10.11/53 and 10.11/804 should be recommended for the cumulative French fries.
\end{abstract}

\section{Introduction}

Potato tubers are processed mainly for crispy potatoes, French fries, starch and mashed potatoes. Each type of processing requires tubers of a certain variety. For example, highstarch varieties (13-18\% or more) are required for processing for starch and alcohol. For processing for food the varieties with increased content of dry matter and low reducing sugars are more suitable.

The manufacturer should remember that the consumer is very discerning to quality. The processing industry has strict standards for raw materials, as the products produced shall be of high quality and at the same time cost-effective. Potatoes used as raw materials for the processing industry shall meet a number of quality requirements: the size and shape of tubers, damage and defects, the dry matter content and color [1].

The shape of tubers, the condition of their surface, the depth of the eyes have a significant impact on the economic indices of processing. The optimal shape of tubers for the production of fries - at least $50 \mathrm{~mm}$ to length. It should be borne in mind that the abrasive cleaning is used in the production lines and when using oblong shape tubers compared to rounded ones there are large wastes. The eyes on the tubers should be superficial, as deep cleaning is required manually, which requires additional workers and

\footnotetext{
*Corresponding author: basiev_s@mail.ru
} 
causes an increase in waste. During mechanical cleaning, the total losses from the main cleaning and subsequent post-treatment can reach up to $25-45 \%$ [2].

An important index of the variety is the color of flesh. For processing, varieties with yellow flesh are preferable. Another important aspect is color uniformity. The uneven color causes the French fries to appear dark at one end. The reason for this is aging (wilting) of tubers and secondary germination.

Some varieties tend to develop "sugar bags" when aging after long-term storage. In cases of strong secondary germination, starch flows from the primary tuber to the secondary germinated tuber. The outflow of starch begins at the bottom of the tuber and can cause liquefaction of flesh. Liquefaction occurs in flesh of the secondary germinated tubers or on top of a long tuber; when cut, it has a watery transparent appearance. Even spongy textures are observed.

Thus, an increase in the production of potato products requires the creation of special varieties. Breeding potatoes for availability for fried potato products industrial processing is associated with certain difficulties due to the need to combine many traits in one genotype. The quality of the finished French fries is of great importance for the content of reducing sugars, on which the color of the resulting product depends, and therefore, breeding work in the direction of creating varieties that do not accumulate them is promising. A large amount of reducing sugars corresponds to the dark color of fried potato products, as well as their bitter taste. Tubers intended for processing should contain $0.25 \%$ sugars max. [3, 4].

In Russia, there are no high-starchy potato varieties, and therefore monitoring the starch content of new varieties is one of the most necessary elements of potato selection for quality. Starch is a mixture of amylose and amylopectin - high molecular polysaccharides, the ratio of which depends on the viscosity, gelatinization, swelling, the ability to gelforming ability. By increasing the content of amylopectin, the brittleness of fried potato products can be reduced [5].

In breeding for high starch content, the selection effectiveness of the parental forms for crossbreeding and phenotypic selection of the breeding material have been proven. Starch accumulation depends on the duration of the potato growing season, and the shorter it is, the less the genes responsible for starchiness can appear themselves [6].

The creation of high-starchy varieties is a laborious task, which is associated with the peculiarity of the cultivated type of potato, which is not characterized by a large degree of starch accumulation. In this regard, the wild species S. chacoense Bitt., S. andigenum Juz. et Buk., S. demissum Lindl. And others are often used in breeding programs. The situation is aggravated by the existence of a negative correlation between yield and starch content.

With an increase in the dry matter content, the industrial processing of potatoes becomes simpler, the quality of the finished product increases, and the fat content decreases in it. The low dry matter content results in watery and soft French fries. However, very high dry matter content can result in a hard consistency in the final product. Tubers prepared for the production of French fries should contain $20-24 \%$ dry matter [7, 8].

\section{Materials and methods}

Potatoes were grown in a mountainous zone (1400 m above sea level, Alagirsky district of North Ossetia - Alania, Kurtat village, the department branch of agriculture, plant growing, selection and seed production of the agronomic faculty of the State Federal-Funded Educational Institution of Higher Professional Training "Gorsky GAU”).

The investigation aim was to evaluate the potato cross-beeds of the State FederalFunded Educational Institution of Higher Professional Training "Gorsky GAU" for availability to industrial processing of French fries. 
The investigation objects are potato cross-breeds of our own selection: 10.2/752 (Bars $\times$ Adretta), 10.2/771 (Bars $\times$ Adretta), 10.11/53 (Roko $\times$ Romano), 10.11/804 (Roko $\times$ Romano), 10.11/1787 (Roko $\times$ Romano), 10.11/1800 (Roko $\times$ Romano).

Potato tubers were evaluated according to the requirements of GOST 26832-86 "Fresh potatoes for food processing" [9]. [2]:

The following calculations and observations were carried out during the experiments

1. The morphological characteristics of potato tubers were determined (according to 9grades scale):

- the shape, size and surface of the tubers were assessed visually. The shape factor of a tuber was calculated as the ratio of its length to width. For French fries, varieties with a long and very long shape are preferred, the factor of which varies from 1.7 to 2 or more. The surface of tubers is flat and smooth. The surface quality was assessed according to the following scale: 9 - smooth; 5 - with shallow indentations (up to $3 \mathrm{~mm}$ ); 3 - with slight warts and cracks (up to $5 \mathrm{~mm}$ ); 1 - with warts and cracks (more than $5 \mathrm{~mm}$ ).

- the number (by calculating) and the depth of the eyes (by measuring with a special ruler) were determined. To reduce waste during cleaning, tubers should have a shallow depth of eyes, and their number should be small.

- assessed the color of the peel and flesh organoleptically, which is important from the consumer point of view. For the production of French fries, yellow meat varieties are preferred, providing a golden color to the finished product. The flesh color varies within the following shades: white, cream, light yellow, yellow, dark yellow.

2. The biochemical indices of potato tubers were assessed: starch and dry matter content by the gravimetric method. The obtained data of dry matter as a percentage ratio were converted into grades, where 16.0-18.0\%\% corresponded to 1-3 grades, $18.1-21.0 \% \%$ - 46 grades, $21.1-24.0 \% \%-7-9$ grades. The starchiness of potatoes affects the taste of the finished product, as well as the consumption of energy and oil.

3. Tubers were assessed for availability for making French fries:

- habit, shape and size of the bars organoleptically, where 9 grades - bars of regular shape, uniform in color and size, 5 grades - bars of uneven size and color with spots occupying $15-20 \%$ of the surface; 1 grade - broken, spotted, irregularly shaped blocks;

- darkening of the flesh of frozen bars organoleptically: from no darkening (9 grades) to very strong (1 grade);

- the consistency of the bars flesh organoleptically.

\section{Results and discussion}

To cook French fries, several tubers were peeled by cutting them into $10 \times 10 \mathrm{~mm}$ pieces. Washed, blanched for 2 minutes, washed again. They were fried until half cooked, cooled, and then frozen in a freezer at a temperature of $-35 \ldots 40{ }^{\circ} \mathrm{C}$. The flesh darkening of the frozen semi-finished product was noted, after which it was fried until completely cooked.

According to the data obtained (Table 1), from the presented samples, a uniform, unexpressed yellow color of the product with no burning was noted in the 10.11/1787 cross-breed. Cross-breeds $10.11 / 53$ and $10.11 / 804$ when roasted give an uneven, unexpressed yellow color. Other cross-breeds form brown spots.

The flesh consistency of all varieties is approximately the same and is characterized by a slight separation between the crust and core, as well as uneven roasting. The difference in taste and smell of cross-breeds is also small and ranges from 5.0 to 6.4 grades. 
Table 1. French fries quality.

\begin{tabular}{|c|c|c|c|c|c|c|c|c|c|c|c|c|c|c|c|c|c|c|c|c|c|c|c|c|}
\hline \multirow{2}{*}{$\begin{array}{l}\text { Cross- } \\
\text { breed }\end{array}$} & \multicolumn{6}{|c|}{ Color, grade } & \multicolumn{6}{|c|}{ Consistency, grade } & \multicolumn{6}{|c|}{$\begin{array}{c}\text { Habit, shape, size, } \\
\text { grade }\end{array}$} & \multicolumn{6}{|c|}{ Taste, smell, grade } \\
\hline & 1 & 2 & 3 & 4 & & avg & 1 & 2 & 3 & 4 & 5 & avg & 1 & 2 & 3 & 4 & 5 & ivg. & 1 & 2 & 3 & 4 & & avg \\
\hline $10.2 / 752$ & 3 & 4 & 3 & 5 & 4 & 3.8 & 5 & 3 & 3 & 6 & 6 & 4.6 & 5 & 6 & 3 & 5 & 6 & 5 & 3 & 7 & 3 & 6 & & 5 \\
\hline $10.2 / 771$ & 2 & 3 & 3 & 2 & 4 & 2.8 & 7 & 4 & 3 & 5 & 7 & 5.2 & 3 & 4 & 3 & 7 & 4 & 4.2 & 7 & 6 & 4 & 4 & & 5.2 \\
\hline $10.11 / 53$ & 6 & 5 & 6 & 4 & 5 & 5.2 & 5 & 4 & 6 & 5 & 7 & 5.4 & 6 & 5 & 5 & 6 & 6 & 5.6 & 7 & 8 & 6 & 5 & 6 & 6.4 \\
\hline $\begin{array}{l}10.11 / 80 \\
4\end{array}$ & 7 & 7 & 4 & 4 & 5 & 5.4 & 7 & 5 & 5 & 4 & 5 & 5.2 & 8 & 5 & 5 & 7 & 5 & 6 & 8 & 6 & 6 & 6 & 4 & 6 \\
\hline $\begin{array}{l}10.11 / 17 \\
87\end{array}$ & 6 & 7 & 6 & 6 & 7 & 6.4 & 7 & 4 & 6 & 6 & 6 & 5.8 & 8 & 7 & 6 & 7 & 7 & 7 & 6 & 6 & 7 & 6 & 7 & 6.4 \\
\hline $\begin{array}{l}10.11 / 18 \\
00\end{array}$ & 2 & 3 & 2 & 3 & 5 & 3 & 5 & 4 & 3 & 5 & 4 & 4.2 & 3 & 3 & 3 & 4 & 4 & 3.4 & 7 & 4 & 5 & 4 & 6 & 5.2 \\
\hline
\end{tabular}

It is noted that in habit, shape and size, the cross-breed 10.11/1787 is superior to other samples, as evidenced by obtaining bars that are fairly uniform in color and size, of the correct shape. Basically, the investigated cross-breeds, when roasted, formed swellings, thinning, spots.

Table 2. The availability assessment of the finished product of cross-breeds for fries processing.

\begin{tabular}{|c|l|c|c|c|c|c|c|c|}
\hline No. & $\begin{array}{c}\text { Flesh } \\
\text { Cross- } \\
\text { breed } \\
\text { darkening } \\
\text { of a frozen } \\
\text { semi- } \\
\text { finished } \\
\text { product, } \\
\text { grade }\end{array}$ & $\begin{array}{c}\text { Color, } \\
\text { grade }\end{array}$ & $\begin{array}{c}\text { Flesh } \\
\text { consiste } \\
\text { ncy, } \\
\text { grade }\end{array}$ & $\begin{array}{c}\text { Habit, } \\
\text { shape, } \\
\text { size, } \\
\text { grade }\end{array}$ & $\begin{array}{c}\text { Taste, } \\
\text { smell, } \\
\text { grade }\end{array}$ & $\begin{array}{c}\text { Dry } \\
\text { matte } \\
\text { r, } \\
\text { grade }\end{array}$ & $\begin{array}{c}\text { Ove } \\
\text { rall } \\
\text { gra } \\
\text { de }\end{array}$ \\
\hline 1 & $10.2 / 752$ & 7 & 3.8 & 4.6 & 5 & 5 & 3 & 4.7 \\
\hline 2 & $10.2 / 771$ & 3 & 2.8 & 5.2 & 4.2 & 5.2 & 3 & 3.9 \\
\hline 3 & $10.11 / 53$ & 6 & 5.2 & 5.4 & 5.6 & 6.4 & 3 & 5.3 \\
\hline 4 & $10.11 / 804$ & 5 & 5.4 & 5.2 & 6 & 6 & 3 & 5.1 \\
\hline 5 & $10.11 / 1787$ & 7 & 6.4 & 5.8 & 7 & 6.4 & 3 & 6.0 \\
\hline 6 & $10.11 / 1800$ & 5 & 3 & 4.2 & 3.4 & 5.2 & 3 & 4.0 \\
\hline
\end{tabular}

According to the data presented in Table 2, the slightly darkening flesh of the frozen semi-finished product complies with the cross-breeds $10.2 / 752$ and 10.11/53 (7 grades each). Other cross-breeds darken moderately, while the 10.2/771 cross-breed darkens strongly, and therefore the color and habit of the finished product were unattractive. We can also characterize the accumulation degree of reducing sugars in cross-breeds according to this index. So, in cross-breeds $10.2 / 752$ and $10.11 / 1787$ it is minimal which is extremely important in the production of fried potato products.

The cross-breeds formed approximately the same amount of dry matter - within 17.1-18 $\% \%$ (due to the short growing season of the investigated samples), which complies with 3 grades when assessing the availability for cooking French fries.

So, according to the overall grade of the finished product availability assessment we should select the cross-breed $10.11 / 1787$ due to the faintly darkening flesh of the frozen semi-finished product, the attractive habit of the finished French fries, their good taste and smell.

It has been specified that according to the morphological grounds of tubers, crossbreeds 10.11/53 and 10.11/804 (7.5 and 6.8 degrees, respectively), characterized by an elongated tuber shape, shallow depth of eyes, and a flat smooth surface of tubers, satisfy 
most of all the requirements for the production of potatoes. Cross-breeds 10.2/771, $10.11 / 1800,10.11 / 1787$ comply with these requirements to a weak degree.

Table 3. The availability assessment of the cross-breeds for fries processing.

\begin{tabular}{|c|l|c|c|c|}
\hline No. & Cross-breed & Tuber grade & Finished product grade & Average \\
& & & & \\
\hline 1 & $10.2 / 752$ & 6.0 & 4.7 & 5.4 \\
\hline 2 & $10.2 / 771$ & 4.5 & 3.9 & 4.2 \\
\hline 3 & $10.11 / 53$ & 7.5 & 5.3 & 6.4 \\
\hline 4 & $10.11 / 804$ & 6.8 & 5.1 & 6.0 \\
\hline 5 & $10.11 / 1787$ & 5.3 & 6.0 & 5.7 \\
\hline 6 & $10.11 / 1800$ & 4.8 & 4.0 & 4.4 \\
\hline
\end{tabular}

According to the overall grade (Table 3), which is calculated by adding the grades obtained in assessing morphological, biochemical parameters, as well as the quality of the finished product, cross-breeds $10.11 / 53$ and 10.11/804 should be recommended for the production of French fries.

\section{Conclusion}

1. The requirements for tubers on morphological grounds for the production of French fries are satisfied by cross-breeds $10.11 / 53$ and $10.11 / 804$, characterized by an elongated form of tuber, flat and smooth surface, shallow depth of the eyes,

2. According to the quality of the finished product we should select the cross-breed $10.11 / 1787$ due to the faintly darkening pulp of the frozen semi-finished product, the attractive appearance of the finished French fries, their good taste and smell.

3. Cross-breeds $10.11 / 53$ and 10.11/804 should be recommended for the cumulative French fries.

\section{References}

1. G. Kuzdra, Potatoes and vegetables, 6, 6 (1986)

2. K. A. Pshechenkov, Methodological guidelines for assessment of potato varieties availability for processing and storage (2008)

3. L. V. Nezakonova, A. P. Pingol, Potato protection, 1, 8 (2011)

4. S. Basiev, T. Lazarov, M. Gaplaev, F. Gerieva, I. Shishkhaev, IOP Conference Series: Earth and Environmental Science, 659, 012085 (2021)

5. G. I. Piskun, L. N. Kozlova, Potato growing: collection of scientific investigation, 52 (2013)

6. V. L. Makhanko, L. N. Kozlova, O. B. Nezakonova, Land husbandry and plant protection, 3, 62 (2013)

7. D. V. Abrosimov, The selection principles of parental pairs and selection methods for breeding potatoes for increased starchiness (2007)

8. N. F. Sintsova, Z. F. Sergeeva, T. A. Osipova, Agricultural science of the Euro-NorthEast, 3, 32 (2015)

9. GOST 26832-86. Fresh potatoes for processing into food. Specifications (2010) 